\title{
Wine origin authentication linked to terroir - wine fingerprint
}

\author{
B. Gabel
}

NightSky Sro., R\&D Department, Bratislava, Slovakia

\begin{abstract}
Global wine and alcohol trade faces a serious economic problem linked to counterfeiting of these commodities. Recently applied authentication methods and techniques pose more difficulties for counterfeiters but they are apparently not effective once we consider economical losses identified by EU legal authorities. The presented solution links isotopic characteristics of the soil, plant, technological intermediate product and the final food product (wine, grapes) on the basis of ${ }^{87} \mathrm{Sr} /{ }^{86} \mathrm{Sr}$ isotopes ratios. For the isotopic signature of wines, the average isotope composition of the substrate cannot be a reliable indicator. Only the isotopic composition of pore water can, as it leaches various mineral phases at different stages and passes into vine root system. Instead of complicated sampling of pore water, an original method of preparing and processing soil samples and consequently must $\&$ wine samples was developed. Based on both, soil and biological material analysis, we can unquestionably determine not only geographical but also regional and local authenticity of the wine. Determination of red wines isotopic signature is more straightforward process in comparison to white wines, because of technologically different processing of grapes. That is the reason why, in case of white vines, the ${ }^{87} \mathrm{Sr} /{ }^{86} \mathrm{Sr}$ ratio of bentonites (natural purifier and absorbent useful in the process of winemaking) must also be taken into consideration. Results of analyses of Slovak wines from geographically diverse regions as well as from sites in close-by distances have clearly established reliability of presented concept, in which the soil is linked to the plant and to the final food product (wine or table grapes).
\end{abstract}

\section{Introduction}

According to EUIPO report (July 2016) the EU's financial losses due to counterfeiting of wines and alcohols are enormous. Estimated direct effect on EU economy is roughly 1.3 billion of revenue lost annually (direct loss of sector sales) corresponding to $3.3 \%$ of the sectors' sales with direct employment losses of cca. 4.800 jobs. Current problem is not "only" counterfeiting of the world's most valuable brands (Château Petrus, Domaine de la Romanée-Conti, Château d'Yquem, ...), but also creation of fraudulent brands under the French AOC or Italian DOCG and even counterfeiting the country of origin (Australia). Science-based solutions to guarantee wine originality have become a highly current and inevitable reality for exporters, not only from the EU.

Conventional authentication methods include: administrative acts (expert testimony, formal report of authentication, since 2018 introduction of e-certificates), forensic processes (DNA markers, chemical trace elements) as well as high-tech solutions (RFID tags, NFC chips, QR codes, etc.). While these measures and techniques make forging more difficult, they are not sufficient to stop it. Official methods to verify authenticity of wine and grapes are based on isotopic techniques. According to the OIV, there are three reference methods for isotopic analysis of wines and musts used in EU Customs Laboratories:

- OIV-MA-AS311-05 Determination ratio of ${ }^{2} \mathrm{H} /{ }^{1} \mathrm{H}$ (SNIF NMR);

- OIV-MA-BS-22 Determination ratio of ${ }^{13} \mathrm{C} /{ }^{12} \mathrm{C}$ (IRMS);
- OIV-MA-AS2-12 Determination ratio of ${ }^{18} \mathrm{O} /{ }^{16} \mathrm{O}$ (IRMS).

In nature, $\mathrm{H}, \mathrm{C}$ and $\mathrm{O}$ isotopes are subject to isotope fractionation, so the resulting ratio is not stable. It is significantly affected by abiotic conditions during vegetation, especially temperature and precipitation. Moreover, the above-mentioned analyses of light stable isotopes are not linked to rock substrate. In regard to the environment they only refer to seasonal isotopic nature of the precipitation. Therefore, strictly speaking, such analyses cannot provide stable information about regional origin. In this context, a large number of different analytical techniques have been and are evaluated [10], [4]. The use of isotope ratios of certain key heavy trace elements is a well-established tool in geology, geochemistry, and cosmochemistry for dating and tracing the origin of rocks [6]. This knowledge has extended applications of isotope geology to many variable areas e.g. environment, archeology, forensic and food science $[11,12]$. The success of this geologic method of regional tracing resides in the fact that no rocks have the same isotopic composition unless they were generated in the same environment and at the same time.

\section{Strontium as trace element}

One of the first works on the isotopic composition of ${ }^{87} \mathrm{Sr} /{ }^{86} \mathrm{Sr}$ in wines was published in the early 1990s [9]. It has shown that there are measurable differences in isotope ratios in wines from different regions and thus, generally speaking, there is possibility to identify regional

(C) The Authors, published by EDP Sciences. This is an Open Access article distributed under the terms of the Creative Commons Attribution License 4.0 (http://creativecommons.org/licenses/by/4.0/). 
origin of wine based on ${ }^{87} \mathrm{Sr} /{ }^{86} \mathrm{Sr}$ isotopic ratio. It was an innovative approach because ${ }^{87} \mathrm{Sr} /{ }^{86} \mathrm{Sr}$ isotope ratio in a given area is bound only to parent rocks. According to the independent Australian federal government agency CSIRO, strontium is a very effective trace element for this kind of analysis, as it distinguishes between different types of ground water and has high concentration in wines. CSIRO has revealed that strontium isotope ratios, combined with other trace elements like boron, barium, cobalt, lithium, manganese, nickel and rubidium, can help distinguish between major wine producing regions in Australia.

The Rb-Sr method was developed at the beginning of the 1950s as a possibility to determine geological age of mainly crustal plutonic and metamorphic rocks. The principle of $\mathrm{Rb}-\mathrm{Sr}$ method is based on the fact that rubidium, commonly present in the earth's crust rocks, is composed of two isotopes: ${ }^{85} \mathrm{Rb}$ and very low-level radioactive isotope ${ }^{87} \mathrm{Rb}$ (27.8 atomic\% in the natural isotope mixture), this one producing a stable ${ }^{87} \mathrm{Sr}$ strontium isotope with a half-life of 48.8 billion years $(\mathrm{Ga})$ during its disintegration. This means that rocks of different age, of different genesis with different $\mathrm{Rb} / \mathrm{Sr}$ concentration ratios will have different ${ }^{87} \mathrm{Sr} /{ }^{86} \mathrm{Sr}$ isotope ratios today. It has been shown very quickly (as early as the mid1960s) that the ${ }^{87} \mathrm{Sr} /{ }^{86} \mathrm{Sr}$ isotope ratio can be used as an important isotope-geochemical indication parameter to address a wide range of origin issues, whether of inorganic or organic materials. Currently, monitoring of strontium isotopic composition in plants and original substrate is defined as observation of the relation between isotopic composition of the geological foundation to the term defined in expert literature as "bioavailable strontium". It should be emphasized that there is no measurable isotopic fractionation while strontium transfers from soil to plants.

All four Sr isotopes are stable, although the fraction of ${ }^{87} \mathrm{Sr}$ varies due to radioactive decay of ${ }^{87} \mathrm{Rb}$. This decay is the basis for the Rb-Sr dating method $[2,7]$. Sr and Rb are trace elements but are common in rock and soil forming minerals because they substitute for $\mathrm{Ca}$ and $\mathrm{K}$. Therefore it is not a problem to identify their concentration by current analytical facilities. The rocks have different chemical and mineral composition consequently the $\mathrm{Rb} / \mathrm{Sr}$ ratio is also different (e.g. granite has higher ratio, basalt lower and carbonates very low). Thus, ${ }^{87} \mathrm{Sr} /{ }^{86} \mathrm{Sr}$ ratio is an indicator of both age and geochemical origin of rocks [2,7].

The real amount of isotope ${ }^{87} \mathrm{Sr}$ is expressed as ratio to isotope ${ }^{86} \mathrm{Sr}$, amount of which is constant in nature, i.e. ratio ${ }^{87} \mathrm{Sr} /{ }^{86} \mathrm{Sr}$. It has quickly emerged that the use of the $\mathrm{Rb}-\mathrm{Sr}$ method can lead to fundamental advances in understanding development of Earth's crust and mantle, but especially in the ability to identify sources of crust rocks, what still to this day poses a major problem in geology. A new trend has emerged, strontium isotope geochemistry, which has provided application possibilities of the method for various research directions, often entirely outside the interests of geology. However, the main focus concentrated on the study of ${ }^{87} \mathrm{Sr} /{ }^{86} \mathrm{Sr}$ isotopic ratio in crust rocks (today's and for geologists mainly the original ratio at time of their emergence) and also in the products of their weathering.

The data obtained over the following years has shown that today's most common isotopic ratios of ${ }^{87} \mathrm{Sr} /{ }^{86} \mathrm{Sr}$ in the crustal rocks (from cca. 0.705 to 0.730 ) result from

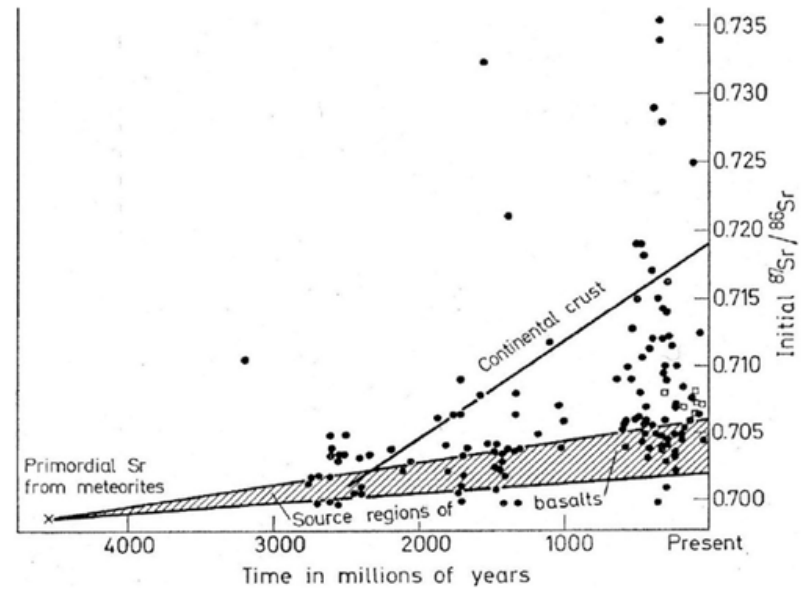

Figure 1. Evolution of ${ }^{87} \mathrm{Sr} /{ }^{86} \mathrm{Sr}$ ratio in Earth's continental crust and mantle [7]. Generally, ${ }^{87} \mathrm{Sr} /{ }^{86} \mathrm{Sr}$ isotopic ratios in wines will vary between $0.705-0.720$.

a combination of: the original, initial ratio of ${ }^{87} \mathrm{Sr} /{ }^{86} \mathrm{Sr}$ at the time of rock formation, the $\mathrm{Rb} / \mathrm{Sr}$ ratio, age of the crustal rock and possible post genetic changes (Fig. 1). This led to the view that it is possible to define isotope-specific regions, and from there came the idea of isotope-geochemical analysis of objects' origin (e.g. agricultural products) in various geographical areas, even outside geology interest. In recent years, a large number of works on ${ }^{87} \mathrm{Sr} /{ }^{86} \mathrm{Sr}$ isotope composition in wine from different wine regions in combination with other additional information have been published. The works stated that isotopic composition of wines "globally" correlates with the parent substrate, but the fact is that the geochemical reality is often more complicated. It has also been unquestionably proven that there are isotopic differences between different regions (even on global scale), but on the other hand, even from extremely different regions, isotopic ratios can come very close, or even be identical. However, such works are very rare from a geochemical perspective.

Older studies have shown the existence of some degree of ${ }^{87} \mathrm{Sr} /{ }^{86} \mathrm{Sr}$ ratio variation in wines from different production areas. $\mathrm{Sr}$ is captured by vine roots together with nutrients, among those leachable and hence available to biovegetative processes. Despite this published data the use of radiogenic isotopes of geological interest for tracing wine provenance was far from being a well-established method yet [11]. Present works show ${ }^{87} \mathrm{Sr} /{ }^{86} \mathrm{Sr}$ ratio measured in must, vine branches or wine are generally consistent with the $\mathrm{Sr}$ isotopic composition of soils and bedrocks. The best match of ${ }^{87} \mathrm{Sr} /{ }^{86} \mathrm{Sr}$ ratio of tested samples is at third and fourth decimal place. The match was getting worse when the product of vine were compared with bulk soil or rock $[1,8]$.

\section{New approach to authentication of wine origin}

Rock substrate represents, mineral-wise and hence isotopically, a very heterogeneous material containing minerals with different $\mathrm{Rb} / \mathrm{Sr}$ ratio, which, additionally, contains a number of secondary minerals. For an isotope signature of wine, average isotope composition of the 


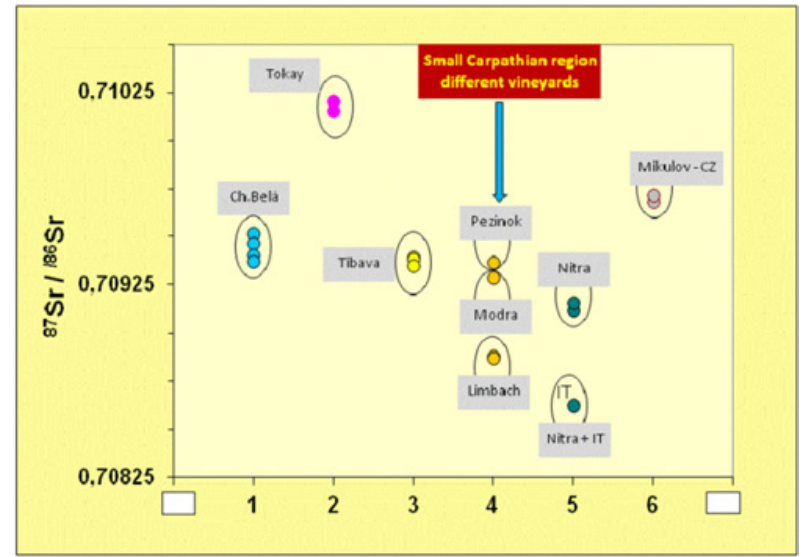

Figure $2 .{ }^{87} \mathrm{Sr} /{ }^{86} \mathrm{Sr}$ ratio In re geographical and regional origin of the Slovak wines. Wine growing regions: 1- South Slovakian, 2-Tokay, 3-East Slovakian, 4-Small Carpathian, 5-Nitra (IT: wine from Nitra with addition of Italian wine), 6-Morava (Czech Republic).

substrate cannot be a reliable indicator. Only isotopic composition of pore water that leaches different mineral phases at different levels and permeates into the vine root system can be. The key difference from previous works is modified procedure for the preparation of soil leachate for ${ }^{87} \mathrm{Sr} /{ }^{86} \mathrm{Sr}$ ratio determination. The ${ }^{87} \mathrm{Sr} /{ }^{86} \mathrm{Sr}$ ratio from soil is compared with the ${ }^{87} \mathrm{Sr} /{ }^{86} \mathrm{Sr}$ ratio of must and wine. The soil develops on bedrock and transmits unique geochemical traces of the bedrock to vine. The must was chosen for analysis, because it represents natural product of vine without technological intervention of the wine producer.

Previous but also current knowledge based on trace element analysis and their comparison in the range of discriminatory analyzes possibilities did not allow for strict division of regions. So far unpublished analyzes of Slovak producers' wines have shown that there are big differences in measured values, which of course reflect regional differences and thus could lead to the identification of wine origin at regional level (Fig. 2).

Figure 2 illustrates, that based on ${ }^{87} \mathrm{Sr} /{ }^{86} \mathrm{Sr}$ ratio determination and the technology of sample processing used by us, it is possible to unequivocally distinguish wines from different wine-growing regions. Distinguishing ability is rather satisfactory, so even wines from the same wine-growing region (4- Small Carpathian region) can be identified on local level: the distance between the winegrowing sites Pezinok-Modra $(7 \mathrm{~km})$, Pezinok-Limbach $(4 \mathrm{~km})$, Modra-Limbach $(11 \mathrm{~km})$. Declared admixture of Italian wine in the wine from Nitra region significantly changed ${ }^{87} \mathrm{Sr} /{ }^{86} \mathrm{Sr}$ ratio of the original production. Wines from a completely different geographic zone (6- Moravia) differed significantly from the wines of Slovak provenance.

In 2017, soil samples were taken from two completely different (in regard to pedology and geology) vineyards in the Small Carpathian wine-growing area, the distance between them being about $5 \mathrm{~km}$ as the crow flies. Standardization of soil sampling from vineyard parcel is a key moment in regard to correct interpretation of measured values and interdependencies between soil, must and wine. Sampling must be carried out at least on 5 different

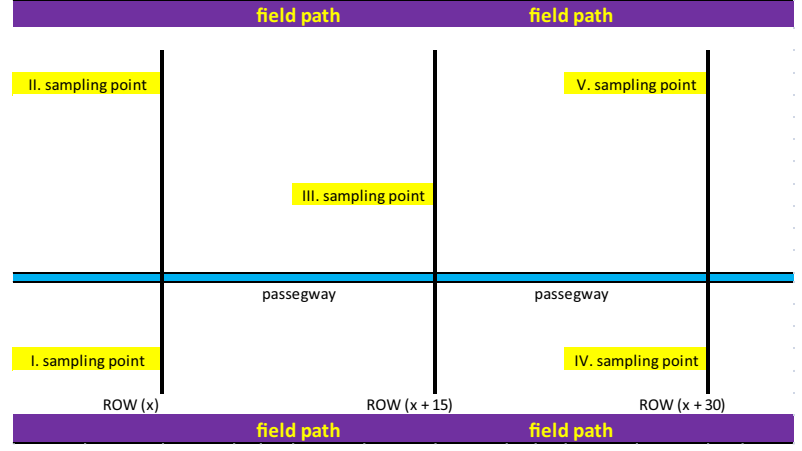

Figure 3. "Checker" placement of soil sampling points from the monitored vineyard.

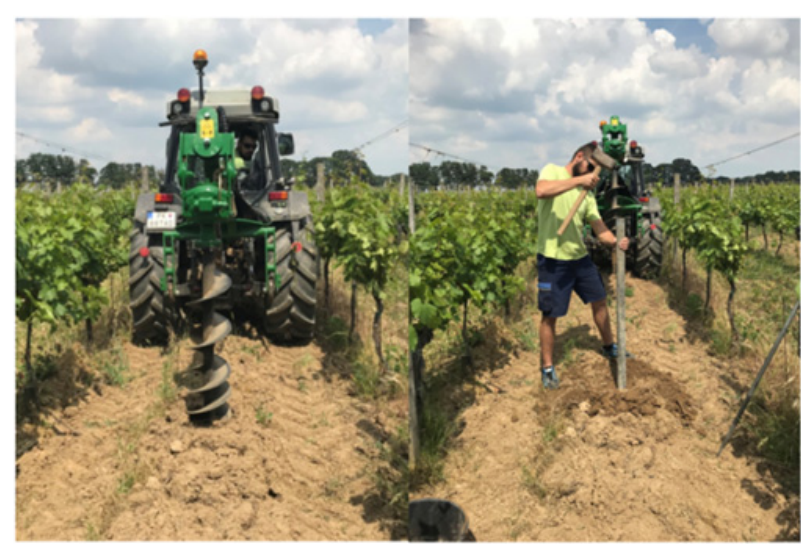

Figure 4. Collection of soil samples is one of the key moments for correct interpretation of measured values of strontium isotopes.

locations in the vineyard from which the raw material for the final product originates - wine or grapes (Fig. 3).

In case the soil is too hard, too compacted from the passages of machinery, it is advisable to plough each sampling point with the help of a ground drill to a depth of $70-80 \mathrm{~cm}$. Subsequently, a thick-walled galvanized iron rod of a known diameter $(5.3 \mathrm{~cm}$ in our case $)$ is driven up to a depth of $60 \mathrm{~cm}$ into the loose soil. This way, we get a representative sample from the entire soil horizon to a depth of $60 \mathrm{~cm}$. Two soil samples are taken from one sampling point (Fig. 4).

The amount of soil collected from the five sampling points is continuously stored in a bucket in order to thoroughly mix the entire soil volume. The sample is then homogenized and quartered, its volume reduced to about $1 \mathrm{dm}^{3}$, and this volume is intended for further processing in the laboratory. In laboratory, the sample is further crushed and sifted through $2 \mathrm{~mm}$ sieve. Soil samples are evaluated on the basis of strontium isotopes ratio in soil extracts. The aim of the extract preparation is to analyze only those forms of strontium which are accessible for the root system. From both sites, samples of must and wine were taken (each sample $-50 \mathrm{ml}$ ). Each type of bentonite used in the vinification process was separately analyzed for the strontium isotope ratio. Sample analysis was performed using standard analytical procedures: process of eluent chromatography on the selected ion exchangers, removal of chemical matrix, isobars and separation of pure strontium and then measurement of isotopic composition of strontium on mass spectrometer in static and dynamic mode. 


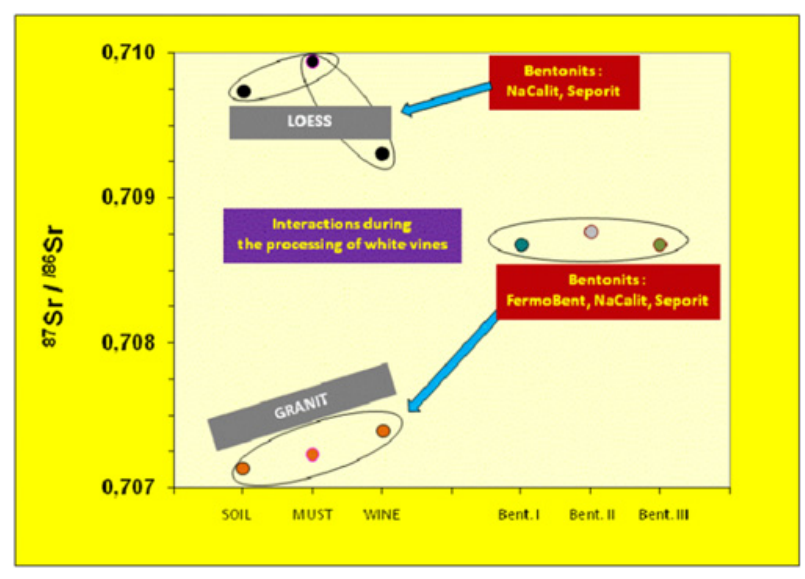

Figure 5. Rheinriesling, vintage 2017, Small Carpathian region. Two different local vineyards on the granite and loess. ${ }^{87} \mathrm{Sr} /{ }^{86} \mathrm{Sr}$ ratio of bentonits used during the process of vinification must be taken into consideration for white wines.

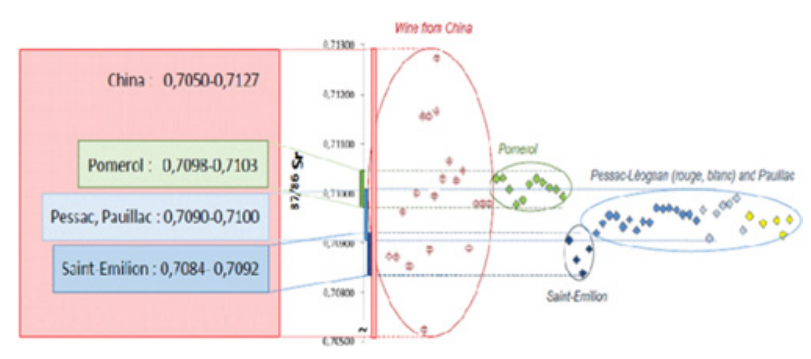

Figure 6. Isotopic signature determination of red wines has significant probative value as the final result of isotope measurements does not get distorted by the vinification process. Source: [5].

Figure 5 clearly shows that the method used for processing soil samples, bentonites as well as musts and wine makes it possible to extract a sufficient and representative volume of strontium from them. In the case of soil, it is the strontium available for root system of vines, clearly shown by close values of ${ }^{87} \mathrm{Sr} /{ }^{86} \mathrm{Sr}$ ratio in soil and must. The results of measurements on the same variety, planted in diametrically different conditions from the geological and pedological point of view (granit versus loess), but topographically relatively close locations (distance about $5 \mathrm{~km}$ as the crow flies), clearly illustrate distinctive ability of our method for purposes of geographical localization of wines not only at regional but also at local level. When evaluating the final product - wine, for white wines it is necessary to require manufacturer's declaration about used bentonite or zeolite-based clarifiers, as they introduce a deviation into evaluation process of the final product compared to the values identified in the soil.

In case of red wines, oenological agents do not enter vinification process, which could somehow modify initial ${ }^{87} \mathrm{Sr} /{ }^{86} \mathrm{Sr}$ ratio in the must, therefore the correlation between terroir and red wine is evident and demonstrably direct (Fig. 6).

\section{Conclusions}

Based on soil and biological material analysis we unquestionably determine not only geographical, but also regional and local authenticity of the vine using original method for processing of soil samples as well as method of sampling in individual stages of plant material processing, which become basis for the final food product.

For the isotopic signature of wines the average isotope composition of substrate cannot be a reliable indicator. Only the isotopic composition of pore water can. It leaches different mineral phases in different stages and passing through the root system of the plant we find that composition also in final food product. Sometimes isotopic composition is modified (processing aspect), but with measurable delta in the case we know exact technological steps of food processing.

The proposed principle of determining strontium ${ }^{87} \mathrm{Sr} /{ }^{86} \mathrm{Sr}$ isotopes in vines and terroir creates a unique, inseparable relationship between the final product and the area it originates from.

\section{References}

[1] E. Braschi, S. Marchionni, S. Priori, M. Casalini, S. Tommasini, L. Natarelli, A. Buccianti, Bucelli, P., Constantini, E.A.C., Conticelli, S., Sci. Total Environ. 628, 1317 (2018)

[2] C. Capo, B.W. Stewart, O.A. Chadwick, Geoderma 82, 197 (1998)

[3] S. Conticelli, J. Agric. Food Chem. 61, 6822 (2013)

[4] G.P. Danezis, A.S. Tsagkaris, F. Camin, V. Brusic, C.A. Georgiou, Trends Anal. Chem. 85, 123 (2016)

[5] E. Epova, S. Bérail, B. Medina, L. Sarthou, O.F.X. Donard, Authenticity testing of wine and tea samples using multi-collector-inductively coupled plasma-mass spectrometry (Mc-ICP-MS). IsoFood Stakeholder workshop, 23.11.2015 (Institut Jožef Stefan, Ljubljana, Slovenija, 2015)

[6] G. Faure, Principles of Isotope Geology (Wiley: New York, 1986), p. 594

[7] G. Faure, J.L. Powell, Strontium Isotope Geology. (Springer Verlag, Berlin-Heidelberg-New York, 1972) pp. 188

[8] L. Ghezzi, I. Arienzo, A. Buccianti, G. Demarchi, R. Petrini, Eur. Food Res. Technol. 244, 1027 (2018)

[9] P. Horn, P. Schaaf, B. Holbach, S. Hölzl, H. Eschnauer, Z. Lebensm Unters Forsch 196, 407 (1993)

[10] M. Lee (Ed.). Food authenticity and traceability. (CRC Press, Woodhead Publishing Limited), http://dx.doi.org/10.1016/B978-1-85573526-2.50004-2 (2003)

[11] S. Marchionni, E. Braschi, S. Tommasini, A. Bollati, F. Cifelli, N. Mulinacci, M. Mattei, S. Conticelli, J. Agric. Food Chem. 61, 6822 (2013)

[12] M. Willmes, C. Bataille, P. James, H.F. Moffat, I. McMorrow, L. Kinsley, L. Armstrong, R.A. Eggins, S., R. Grün, Appl. Geochem. 90, 75 (2018) 